\title{
Technical note: Validation and comparison of 2 commercially available activity loggers
}

\author{
Per Peetz Nielsen, ${ }^{* 1}$ Ilaria Fontana, $†$ Karen Helle Sloth, $\ddagger$ Marcella Guarino, $†$ and Harry Blokhuis $\S$ \\ *Department of Large Animal Sciences, University of Copenhagen, Grønnegårdsvej 8, DK-1870 Frederiksberg C, Denmark \\ †Department of Environmental Science and Policy, Università degli Studi di Milano, Via Celoria 2, 20133 Milano, Italy \\ ‡GEA Farm Technologies GmbH, Siemensstraße 25, DE-59199 Bönen, Germany \\ $\S$ Department of Animal Environment and Health, Swedish University of Agricultural Sciences, PO Box 7068, SE-750 07 Uppsala, Sweden
}

\section{ABSTRACT}

To validate the accuracy of 2 commercially available activity loggers in determining lying, standing, walking, and number of steps in dairy cows, 30 cows were fitted with the CowScout Leg (GEA Farm Technologies, Bönen, Germany) system and the IceTag (IceRobotics Ltd., Edinburgh, Scotland) system. The CowScout Leg logger reports standing and lying in 15-min periods, whereas the IceTag logger reports standing and lying every second. To make data comparable, the IceTag data were therefore also summarized over 15 -min periods corresponding to the paired CowScout Leg sensor. These data from the 2 systems were then analyzed (more than 1,000 cow days in total). Video recordings of a total of $29.5 \mathrm{~h}$ were used for labeling the behaviors of the selected cows $(n=10)$ and these labels were used as a gold standard to determine the accuracy with which these 2 loggers can record behavioral states lying, standing, walking, and the behavioral event number of steps. A concordance correlation coefficient analysis showed that both the standing and lying durations obtained with the 2 systems were almost perfectly correlated with the video labeling (IceTag: $\rho_{\mathrm{c}}=0.999$ and 0.999, respectively; CowScout Leg: $\rho_{\mathrm{c}}=0.995$ and 0.996, respectively). However, both loggers performed poorly regarding number of steps (classified as an event; IceTag: $\rho_{\mathrm{c}}=0.629$; CowScout Leg: $\left.\rho_{\mathrm{c}}=0.678\right)$ and CowScout Leg did not detect walking (classified as a state) very accurately $\left(\rho_{c}=0.860\right)$. The IceTag system does not measure walking behavior. When comparing the 2 loggers, the correlation between them for standing and lying was substantial $\left(\rho_{\mathrm{c}}=0.953\right.$ and $\rho_{\mathrm{c}}$ $=0.953$, respectively). The number of steps poorly correlated between the 2 loggers $\left(\rho_{\mathrm{c}}=0.593\right)$, which might

Received September 4, 2017.

Accepted February 16, 2018.

${ }^{1}$ Corresponding author: ppn@sund.ku.dk be due to the CowScout Leg logger being attached to the front leg and the IceTag logger being attached to the hind leg. We conclude that both the IceTag and the CowScout Leg logger are able to record standing and lying almost perfectly, but the step counting by both loggers and the walking recording by the CowScout Leg logger are not very accurate.

Key words: activity logger, dairy cow, validation

\section{Technical Note}

The recent decade's increases in dairy herd size have led to an increased demand for automated systems for monitoring the behavior of cows within dairy production. These systems have become increasingly important for management routines and for monitoring health and welfare on an individual basis. Development in technology gives new opportunities for monitoring of behavior and changes in general activity measured with activity meters for detecting health problems; for example, an increase in lying bout duration can indicate a potential hoof problem in dairy cows (Thomsen et al., 2012; Thorup et al., 2015; Beer et al., 2016).

Several activity meters are currently available that can differentiate between lying, standing, and walking behavior (Pastell et al., 2009; de Passillé et al., 2010; Ledgerwood et al., 2010), measure grazing behavior (Nielsen, 2013), monitor lameness problems (Thorup et al., 2015; Beer et al., 2016), and indicate real-time position of each cow in the barn using either wireless local area network signals (Wolfger et al., 2017) or ultra-wide-band signals (Tullo et al., 2016). Each of these systems has huge potential in improving health monitoring of the animals in real time, and recently focus has shifted toward combining these loggers to improve the accuracy in detecting abnormalities (Beer et al., 2016).

The aims of this study were to validate 2 commercially available activity loggers against video labeled data and, furthermore, compare activity classifications and step count between the 2 activity loggers. 
Both IceTag (IceRobotics Ltd., Edinburgh, Scotland) and CowScout Leg (GEA Farm Technologies, Bönen, Germany) sensors were mounted on 30 individual cows in a Swedish commercial 180-cow herd with automatic milking (IceTag sensor on left hind leg, CowScout Leg on left front leg as recommended by the 2 manufacturers). Cows were selected according to parity (10 per parity group 1,2 , and $3+$, and even distribution across early (DIM <40), mid $(40 \leq \mathrm{DIM} \leq 150)$, and late $(\mathrm{DIM}>150)$ stages of lactation (average DIM \pm SD: $22 \pm 10,81 \pm 21$, and $203 \pm 32$, respectively). The cows were followed until leaving the production or for a maximum of 5 mo. Sensor data were logged continuously from January until June 2015 [number of days with recorded data per cow $=72.6 \pm 40.5 \mathrm{~d}$ (mean \pm $\mathrm{SD})$. IceTag data were stored on the sensor devices until transferred wirelessly to a laptop approximately once per month using the USB-connected IceReader download station. CowScout Leg data were logged on a local working station via an Ethernet connection to the CowScout Leg receiver. The time used to initiate the 2 types of loggers on the 2 laptops was synchronized to minimize the potential problem with having a different time between the 2 systems. Output from the IceTag sensor included standing and lying and number of steps in one second resolution (Nielsen et al., 2010), whereas output from the CowScout Leg sensor provided one observation per $15 \mathrm{~min}$ of the classified behaviors summarized to the nearest minute of standing, walking, and lying and number of steps counted.

Ten selected cows (mean DIM \pm SD: $122 \pm 90$ d; parity $1=4$ cows, $2=3$ cows, $3+=3$ cows, respectively), out of the original 30 cows, were selected on parity and DIM to ensure a good variation, and were marked with a letter on the back and on both flanks, and their behavior was video recorded on 2 computers using a digital surveillance system (MSH Video Server v:5.0.11.332, MSH-Video, Riga, Latvia) with 10 cameras (TVCCD-140IR, Monacor, Vittsjö, Sweden) mounted in such a way that all marked cows could be followed at any time.

The video sequences were selected during daytime across the days included in the video, and total video recordings used for the behavioral observations lasted for $29.5 \mathrm{~h}$ with a variable frames per second between 4 and 8 frames per second due to the setting of the video software.

Video recordings were manually analyzed in playback mode using the MSH-Video Client program, a sophisticated software to review and analyze video previously recorded. Video labeling is the precise detection of the occurrence of specific behaviors performed by a single animal or groups of animals (Tullo et al.,
2013). Recordings were decoded and labeled by one trained operator, viewing the videos recorded at the farm and observing them frame by frame (Ismayilova et al., 2013). One of the strengths of this program is the interface layout that displays one or many frames/ viewlets (called cameos) to show the video. This allows the operator to continuously following the marked cows without any blind shooting angle. Moreover, the area can be dragged to a second monitor, if installed. The program also enables speeding up the videos to accelerate the labeling procedure and to slow down the video when the labeler has to focus his/her attention on a specific behavior.

A total of $33 \mathrm{~h}$ of video recordings were visually processed (video labeling), following the marked cows' behaviors and positions. As video was summarized in the same 15-min time slots as the sensor data only some of the labeled video records were used (in total $29.5 \mathrm{~h}$ ). The videos were analyzed to determine the time and position of the cows, checking it frame by frame to precisely detect the start and end time of the behavior/position. The behavioral states recorded were "standing in the alley," "walking in the alley, the cow is moving, not standing still," "lying in the cubicles," and "standing in the cubicles" (when at least 2 legs were in the bed). The behavioral event "number of steps" were also taken into account, but these was counted and did not have a start and end time as the other behaviors recorded. Every time one of the behaviors under consideration was observed and labeled, data such as type of behavior, position, start time, end time, and duration time were reported in a general data set. Moreover, they were classified second by second; more precisely, an activity lasting $10 \mathrm{~s}$ was recorded in the data set as 10 repeated activities of $1 \mathrm{~s}$ as described in Tullo et al. (2016).

To match the 15-min resolution of the CowScout Leg sensor, both video-labeled behavior and IceTag records were summarized in 15-min periods corresponding to the 15-min periods of the paired CowScout logger within animal, adding up number of seconds the IceTag recorded standing and lying and recalculating this to minutes and seconds. The number of steps per $15 \mathrm{~min}$ was summarized from number of steps per second. Before the statistical evaluation, 3 data sets were prepared: video and IceTag data to validate IceTag [6 focus animals, a total of 79 observations of 15 min duration; 13.2 \pm 6.215 min observations per cow (mean $\pm \mathrm{SD})$ ], video and CowScout Leg data to validate CowScout [10 focus animals, a total of 118 observations of 15 min duration; $11.8 \pm 5.415$ min observations per cow (mean $\pm \mathrm{SD})$ ], and IceTag and CowScout Leg data to compare the 2 loggers to each other (28 animals, 247,426 observations 
Table 1. Summary of the number of 15-min observations recorded in each of the 3 data sets used for the analysis as well as the range (min) of standing, lying, and walking recorded in each observation, and the number of steps recorded ${ }^{1}$

\begin{tabular}{|c|c|c|c|c|c|c|}
\hline \multirow[b]{2}{*}{ Data set } & \multicolumn{2}{|l|}{ Number } & \multirow[b]{2}{*}{ Behavior type } & \multicolumn{3}{|c|}{$\begin{array}{c}\text { Range } \\
(\text { min or steps per } 15 \mathrm{~min})^{2}\end{array}$} \\
\hline & Total observations & Cows & & Video & IceTag & CowScout Leg \\
\hline Video vs. IceTag & 79 & 6 & $\begin{array}{l}\text { Standing } \\
\text { Lying } \\
\text { Steps }\end{array}$ & $\begin{array}{l}0-15 \\
0-15 \\
0-99\end{array}$ & $\begin{array}{l}0-15 \\
0-15 \\
0-65\end{array}$ & \\
\hline Video vs. CowScout Leg & 118 & 10 & $\begin{array}{l}\text { Standing } \\
\text { Walking } \\
\text { Lying } \\
\text { Steps }\end{array}$ & $\begin{array}{l}0-15 \\
0-2 \\
0-15 \\
0-124\end{array}$ & & $\begin{array}{l}0-15 \\
0-2 \\
0-15 \\
0-156\end{array}$ \\
\hline IceTag vs. CowScout Leg & 247,426 & 28 & $\begin{array}{l}\text { Standing } \\
\text { Lying } \\
\text { Steps }\end{array}$ & & $\begin{array}{l}0-15 \\
0-15 \\
0-319\end{array}$ & $\begin{array}{l}0-15 \\
0-15 \\
0-666\end{array}$ \\
\hline
\end{tabular}

${ }^{1}$ IceTag (IceRobotics Ltd., Edinburgh, Scotland), CowScout Leg (GEA Farm Technologies, Bönen, Germany).

${ }^{2}$ Standing, walking, and lying were recorded in minutes per $15 \mathrm{~min}$; steps were recorded as number of steps per $15 \mathrm{~min}$.

of 15 min duration; Table 1). In the comparison between IceTag and CowScout Leg, all video-labeled behavioral types different from lying were categorized as standing. Due to occasional malfunctions during downloading the information from the IceTag logger, only data from 6 cows could be included in the video validation.

The statistical examination focused on measuring the agreement between video-and-sensor and sensorand-sensor by calculating the concordance correlation coefficients using the Proc IML procedure in SAS 9.4 (SAS Institute Inc., Cary, NC) for all possible comparisons. The experimental unit was the individual 15-min period. The analysis was applied to both individual cows but also pooled data of all cows, however in the results the focus is on the outcome of the pooled data analysis. The concordance correlation coefficient $\left(\rho_{c}\right)$ by Lin (1989) is a measure of how well bivariate data $(\mathrm{X}, \mathrm{Y})$ agrees. It includes both a measure of precision in terms of the Pearson correlation coefficient and a measure of accuracy given by a bias factor that measures the degree to which pairs of observations fall on the 45 degree line through the origin (Lin, 1989). The $\rho_{\mathrm{c}}$ value from the concordance correlation ranges from 0 to \pm 1 and is suggested by McBride (2005) to be interpreted as follows: $<0.90=$ poor correlation, $0.90-0.95=\bmod -$ erate correlation, $0.95-0.99=$ substantial correlation, and $>0.99=$ almost perfect correlation.

The analysis clearly showed that both the IceTag and the CowScout Leg loggers measure standing and lying duration with an almost perfect correlation with the video labeling (Table 2 ) with very little or close to zero variation between the cows (Table 2). Previous studies involving IceTag have shown the same high correlation of lying and standing in dairy calves (Trénel et al., 2009) and dairy cows (Nielsen et al., 2010). It can therefore be concluded that even the newer CowScout Leg logger with the high concordance correlation coefficient has the same high level of accuracy and precision when recording lying and standing, even though this logger accumulates the behavior into 15-min periods. The somewhat lower, but still substantial, correlation between the 2 loggers when recording lying and standing might be explained by the different recording methods. CowScout Leg accumulates the behavior into 15-min periods and IceTag records every second. Even though the recordings from the IceTag logger were accumulated afterward in SAS, the 2 different calculated accumulations could have affected the correlation between the 2 loggers, for example, due to possible differences in time synchronizations between the 2 loggers, even though the 2 laptops used for initiating the 2 loggers were time synchronized.

The poor step count by both loggers (Table 2) might be explained by the difficulties the observer has in counting leg movements from video recordings when the cow is not walking. However, the poor correlation between the 2 loggers in recording steps are more likely to be explained by 1 logger being attached to the front leg and the other to the hind leg, especially if leg movements not associated with walking are sometimes recorded as steps by the logger as described by Nielsen et al. (2010), or it could simply be a result of the 2 different algorithms for calculating steps used in the 2 loggers, but further studies are needed to validate the difference between attaching the logger on the front or hind leg. Furthermore, the IceTag logger has previously been found to have a high correspondence with counting steps from video recordings of cows walking but not when the cow is standing (Nielsen et al., 2010). A correct estimation of number of steps has the potential 
Table 2. The estimated concordance correlation coefficient $\left(\rho_{c}\right)$ with the lower and upper $95 \%$ confidence limits for each of the 3 data sets and their corresponding behavior types ${ }^{1,2}$

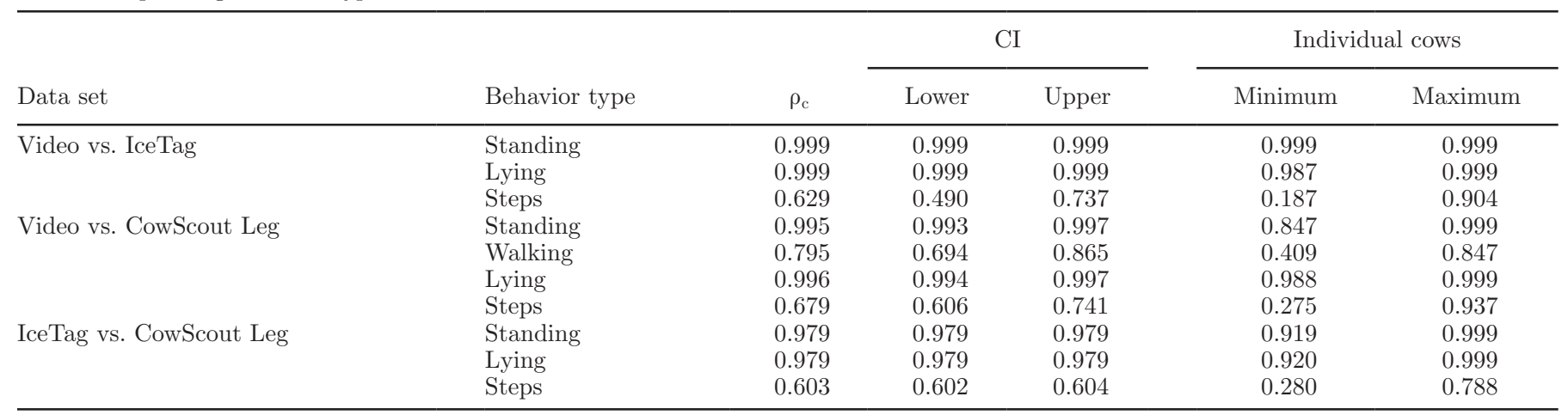

${ }^{1}$ The minimum and maximum concordance correlation coefficients from the individual cows are shown to give information about the individual range.

${ }^{2}$ IceTag (IceRobotics Ltd., Edinburgh, Scotland), CowScout Leg (GEA Farm Technologies, Bönen, Germany).

to be used as an indicator of hoof problems because a shorter stride duration have been associated with increased hoof problems (Flower and Weary, 2006). However, further studies are needed to evaluate the ability of the logger to detect steps in different part of the barn, both when standing and when walking, and how such an information can be used to detect hoof problems in cattle.

Walking was rather poorly recognized by the CowScout Leg logger, whereas IceTag did not record walking but only steps taken (Table 2). This poor recognition can have been due to the fact that walking is typically a transient behavior with a short range duration (0-2 min, Table 2) and this is difficult to evaluate using the resolution of nearest minute as used by the CowScout Leg logger. The duration of the recorded behaviors from the CowScout Leg logger is a rounded number of minutes between 0 and 15 min, whereas the duration of the same behaviors labeled from the video is not rounded to the nearest minute.

In conclusion, the IceTag logger and the new activity logger, CowScout Leg, can recognize standing and lying with almost perfect accuracy, but they both have a problem with determining the number of steps taken. Furthermore, the CowScout Leg logger does not recognize walking to such accuracy as would be acceptable for research purposes.

\section{ACKNOWLEDGMENTS}

This project was funded by European project no. 311825 EU-PLF (Animal and Farm-Centric Approach to Precision Livestock Farming in Europe). Co-financed by the European Commission (Brussels, Belgium). The views expressed in this publication are the sole responsibility of the author(s) and do not necessarily reflect the views of the European Commission. Neither the European Commission nor any person acting on behalf of the Commission is responsible for potential uses of this information. The information in this document is provided with no guarantee or warranty that the information is fit for any particular purpose. The user thereof uses the information at his or her sole risk and liability.

\section{REFERENCES}

Beer, G., M. Alsaaod, A. Starke, G. Schuepbach-Regula, H. Müller, P. Kohler, and A. Steiner. 2016. Use of extended characteristics of locomotion and feeding behavior for automated identification of lame dairy cows. PLoS One 11:e0155796.

de Passillé, A. M., M. B. Jensen, N. Chapinal, and J. Rushen. 2010. Technical note: Use of accelerometers to describe gait patterns in dairy calves. J. Dairy Sci. 93:3287-3293.

Flower, F. C., and D. M. Weary. 2006. Effect of hoof pathologies on subjective assessments of dairy cow gait. J. Dairy Sci. 89:139-146.

Ismayilova, G.. A. Costa, I. Fontana, D. Berckmans, and M. Guarino. 2013. Labelling the behaviour of piglets and activity monitoring from video as a tool of assessing interest in different environmental enrichments. Ann. Anim. Sci. 13:611-621.

Ledgerwood, D. N., C. Winckler, and C. B. Tucker. 2010. Evaluation of data loggers, sampling intervals, and editing techniques for measuring the lying behavior of dairy cattle. J. Dairy Sci. 93:5129-5139.

Lin, L. I. 1989. A concordance correlation coefficient to evaluate reproducibility. Biometrics 45:255-268.

McBride, G. B. 2005. A proposal for strength-of-agreement criteria for Lin's concordance correlation coefficient. NIWA Client Report HAM2005-062.

Nielsen, L. R., A. R. Pedersen, M. S. Herskin, and L. Munksgaard. 2010. Quantifying walking and standing behaviour of dairy cows using a moving average based on output from an accelerometer. Appl. Anim. Behav. Sci. 127:12-19.

Nielsen, P. P. 2013. Automatic registration of grazing behaviour in dairy cows using 3D activity loggers. Appl. Anim. Behav. Sci. 148:179-184. 
Pastell, M., J. Tiusanen, M. Hakojärvi, and L. Hänninen. 2009. A wireless accelerometer system with wavelet analysis for assessing lameness in cattle. Biosyst. Eng. 104:545-551.

Thomsen, P. T., L. Munksgaard, and J. T. Sørensen. 2012. Locomotion scores and lying behaviour are indicators of hoof lesions in dairy cows. Vet. J. 193:644-647.

Thorup, V. M., L. Munksgaard, P. E. Robert, H. W. Erhard, P. T. Thomsen, and N. C. Friggens. 2015. Lameness detection via legmounted accelerometers on dairy cows on four commercial farms. Animal 9:1704-1712.

Trénel, P., M. B. Jensen, E. L. Decker, and F. Skjøth. 2009. Technical note: Quantifying and characterizing behavior in dairy calves using the IceTag automatic recording device. J. Dairy Sci. 92:3397-3401.
Tullo, E., I. Fontana, D. Gottardo, K. H. Sloth, and M. Guarino. 2016. Technical note: Validation of a commercial system for the continuous and automated monitoring of dairy cow activity. J. Dairy Sci. 99:7489-7494.

Tullo, E., I. Fontana, and M. Guarino. 2013. Precision livestock farming: An overview of image and sound labelling. Katholieke Universiteit Leuven, Leuven, Belgium.

Wolfger, B., B. W. Jones, K. Orsel, and J. M. Bewley. 2017. Technical note: Evaluation of an ear-attached real-time location monitoring system. J. Dairy Sci. 100:2219-2224. 